\title{
Effects of MSW selective collection on waste-to-energy strategies
}

\author{
E. C. Rada \\ Department of Civil Environmental Engineering and Mechanics, \\ University of Trento, Italy
}

\begin{abstract}
This paper analyses the effects of the evolution of the selective collection of municipal solid waste on the local strategies for their energy valorization, referring to a case study where high efficiencies of source separation have been reached thanks to a two-decade effort. Four years were characterized as representative of significant moment in the local waste management history. The case study area concerns a province in the North of Italy where particular attention has been put to the organization of selective collection. The economy of the area is typical of a high-income country for all the analyzed period. As expected, these characteristics gave a good steadiness to the composition of municipal solid waste, but the variability of selective collection (which increased its efficiency year by year) affected year by year the characteristics of the residual municipal solid waste. The high efficiency of selective collection that the latest data pointed out causes an indirect modification of the residual municipal solid waste that today is similar to a solid recovered fuel. In spite of its high Lower Heating Value, the energy exploitable, compared to the one of the municipal solid waste generated, is significantly reduced as an effect of source separation (of fractions with significant energy content). Moreover, the reduced power (GJ per year) associated to the present residual municipal solid waste decreases the scale of the provincial plant to a value that must be carefully analyzed in terms of economic viability. From another point of view, the alteration of the residual municipal solid waste characteristics makes it similar to a solid recovered fuel even without pre-treatments. The option for its cocombustion in existing industrial plants (cement factories, thermal power plants, etc.) should be analyzed comparatively.

Keywords: MSW, selective collection, SRF, waste-to-energy.
\end{abstract}




\section{Introduction}

The modern society in the industrialized countries is characterized by a high level of welfare, accompanied by a high consumption of goods and products. The economical development during the years had an important role in the behavior of citizens. Today, they are first of all consumers and thus they consume, in the etymological sense of the term, matter and energy [1]. For this reason, the waste is considered as one of the most important indicators of socioeconomic development of a country $[2,3]$.

The waste concept is strongly connected with the people. The first data regarding the people waste production referred to the Paleolithic era, thanks to the Absolon discovery from 1945 [4]. The first concept of waste selective collection (kerbside) and open dumps constructed at about $2 \mathrm{~km}$ away from the cities, date back to the birth of the first civilization in $2000 \mathrm{BC}$ [5]. After the war and with the economical-industrial development and consequent pollution, some environmental limits and indications regarding waste collection, treatment and landfilling (422/75/EC, 94/62/EC) were developed and implemented.

The waste selective collection (SC) during the years has been one of the most discussed arguments in the scientific sector [6-8]. The first proposed treatment for the selected organic waste was the composting one [9, 10], followed by anaerobic digestion applied first to fruit waste [11] and then to organic waste $[12,13]$. After few experiences around the world, in the 60 s the incineration was massively proposed in order to treat the various kinds waste [14].

In the 2000 thanks to the good development of the biostabilization treatment applied to leachate [15], this treatment was proposed also for municipal waste [16]. In the following years also a new treatment, named biodrying was implemented for municipal solid waste (MSW) treatment in order to generate a combustible material starting from raw MSW [17, 18] even if generally it was previously used mainly for manure waste [19].

In the latest years the MSW sector paid more and more attention to the energy optimization and environmental impact minimization of the above-mentioned processes [20-22]. Recently selective collection increased its role in many countries for many fractions [23-26] as an integrated option of the conventional processes, showing an important impact on the management of the residual MSW.

In this frame, the aim of this paper is to analyze the consequences of the evolution of the MSW selective collection towards the strategies of waste-toenergy, referring to an Italian case study where the MSW management has shown significant changes in the last two decades.

\section{Materials and methods}

In order to give an overview of the waste SC development in the years and the consequences of its implementation on waste-to-energy strategies, a case study from the North part of Italy was selected, referred to a 500,000 inhabitant area. The involved territory is characterized by a significant richness of data in the 
MSW sector. This is the consequence of a political choice that allowed opening a specialized agency for "observing" the waste sector in order to maximize mass valorization before facing with the implementation of a waste-to-energy plant.

In the selected case study, with the introduction of the national legislations 915/1982 (regarding waste in general), 599/1987 (regarding regional waste management plant) and 475/1988 (regarding waste landfilling) SC had to be implemented starting from a near zero efficiency. The consequences can be seen in the data reported in the waste management plans issued in the last two decades: data from the years 1994, 2001, 2004 and 2010 were analyzed in order to extract the information needed for characterizing the local dynamics of the MSW sector. In Figure 1 the composition of MSW is shown pointing out the present situation (first bars) and comparing that to the previous years. In 2001 and 1994 green waste was not classified; this is the reason why the 1994 bar for food waste is the highest. The economy of the area is typical of a high-income country for all the analyzed period: as expected, the characteristics gave a good steadiness to the composition of municipal solid waste in the referring years.

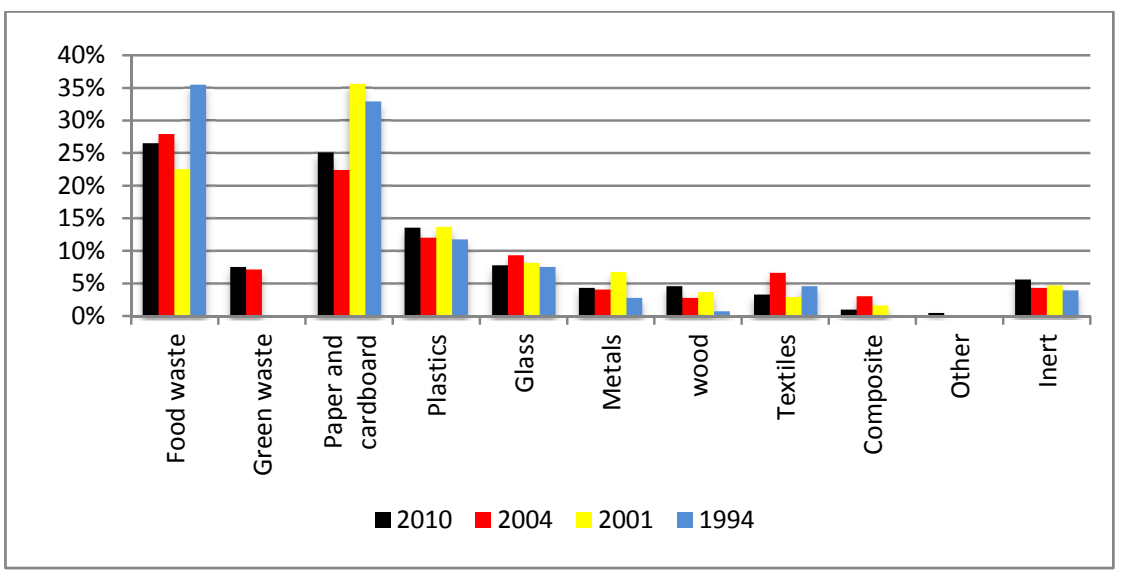

Figure 1: $\quad$ MSW composition during the last two decades.

According to the waste management plans, in the oldest scenario SC was negligible and the sector was dominated by landfilling with no biogas valorization.

The scenario in 2001 was similar in terms of MSW composition but the enforcement of the Italian Ronchi's Decree accelerated the evolution of SC, also including the food waste collection. This stream was not yet associated to the construction of anaerobic digesters as the incentive scenarios were not yet favorable.

In 2004 the construction of a centralized incinerator for the valorization of the residual MSW (RMSW) was planned and under discussion. The SC of materials with high biodegradability and moisture content increased reaching about half of the available steams. 
In 2010, the incinerator construction delayed, but the management of the growing amounts of food and green waste selectively collected was clearly associated to the planning of 4 anaerobic digesters (two of them started their activity in 2012) mostly coupled with post-composting after biogas exploitation. The obtained results in diverting biodegradable materials from landfilling were and are in agreement with the EU landfilling directive. The new legislation for the Solid Recovered Fuel (SRF) from MSW, implemented in Italy in 2010 [18, 27], reopened the discussion about the use of RMSW as a SRF-like in different co-combustion plants already existing also out of the provincial territory.

Summing up, in spite of an apparently steady composition of MSW, the variation of the characteristics of RMSW as a result of SC implementation has progressively changed the perspectives for its treatment. Useful parameters for understanding this evolution are the Lower Heating Value (LHV) of RMSW, the rate of exploitable energy of MSW as RMSW, the SRF similarities of the latter, the food waste content in RMSW. All these parameters were assessed for the four years of reference.

\section{Results and discussion}

Figure 2 shows data related to each of the considered years, concerning the dynamics of the RMSW composition. The decrease of the food waste percentage as consequence of source separation is clear. A higher LHV of RMSW has to be expected.

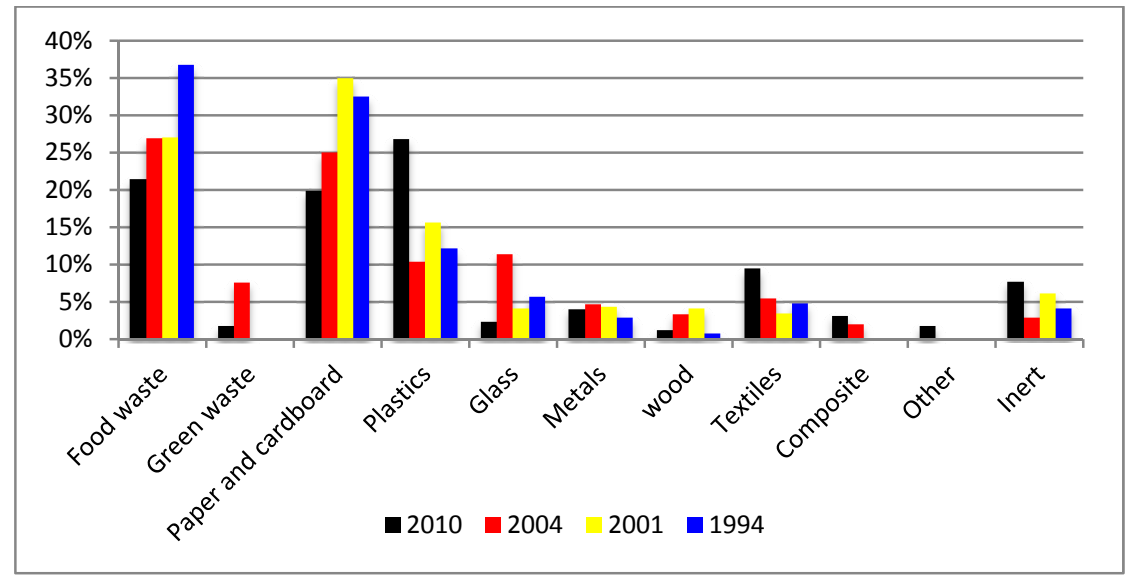

Figure 2: $\quad$ RMSW composition during the last two decades.

Figure 3 reports the trend of SC of the most important streams. The citizen behavior evolution is remarkable: for instance, about 20 years ago the rate of source separation of paper and cardboard was around 5\% whilst today is higher than $75 \%$. Also food waste segregation changed significantly: from zero to around $75 \%$. Concerning this last stream, a target of $85 \%$ is expected, to be 
applied to a generation of $60,000 \mathrm{t} / \mathrm{y}$. Assuming a conversion rate of $0.060 \mathrm{Nm}^{3}$ di $\mathrm{CH}_{4}$ per $\mathrm{kg}$ of food waste fed in the planned digesters, the potential production of methane is around 3 millions of cubic meters per year. An efficiency of electrical conversion as $40 \%$ could give a yearly generation of electricity around 12 million of $\mathrm{kWh}_{\mathrm{el}}$.

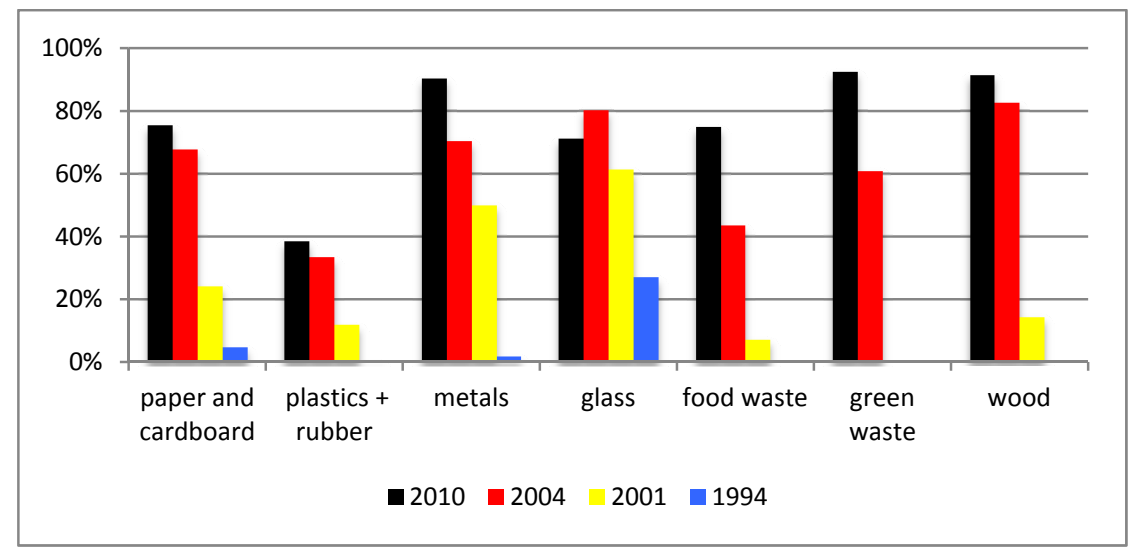

Figure 3: $\quad$ SC during the last two decades (percentage of interception).

In Figure 4, data on LHV of MSW and RMW are reported for the four years. The present situation points out how SC has recently increased the LHV of RMSW compared to the one of MSW. To remarks can be made:

- the initial value of LHV (1994) was already adequate for direct combustion; this had to be expected as the studied area was classified as high income economy also in the $90 \mathrm{~s}$;

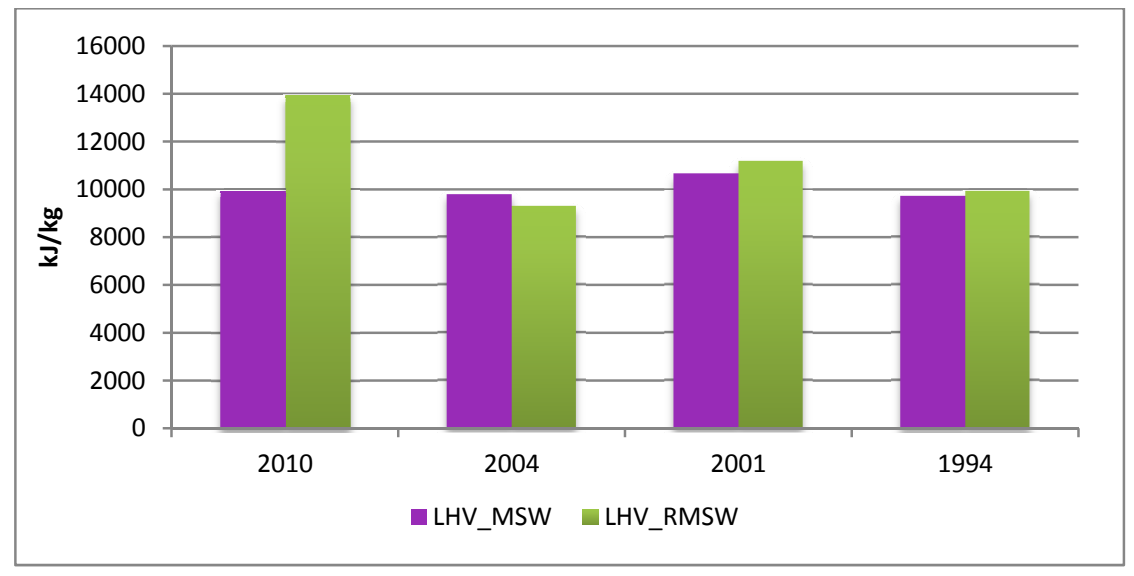

Figure 4: $\quad$ LHV of MSW and RMSW during the last two decades. 
- the "concentration" of energy in the RMSW of 2010 cannot be the unique parameter to be taken into account for analyzing the energy viability of the present scenario; indeed another aspect to be considered is the ratio between the energy available in 1 ton of MSW and the energy available in the respective amount of RMSW.

This last aspect is presented in Figure 5 where it is clear that the higher is SC, the lower is the energy exploitability rate, as a consequence of the segregation of waste fractions with a positive energy content (plastics, paper and cardboard in particular). Taking into account the MSW per capita amount of 2010 (469 kg inh $\left.^{-1} \mathrm{y}^{-1}\right)$, the SC rate $(65 \%)$, the population with tourists expressed as resident equivalents $(574,373)$ and the LHV of RMSW $(13,939 \mathrm{~kJ} / \mathrm{kg})$, an expected net electricity generation from incineration as $25 \%$, the electricity generable from RMSW in the case study is around 91,300,000 $\mathrm{kWh}_{\mathrm{el}} /$ year (about 8 times higher than the one expected from the digesters).

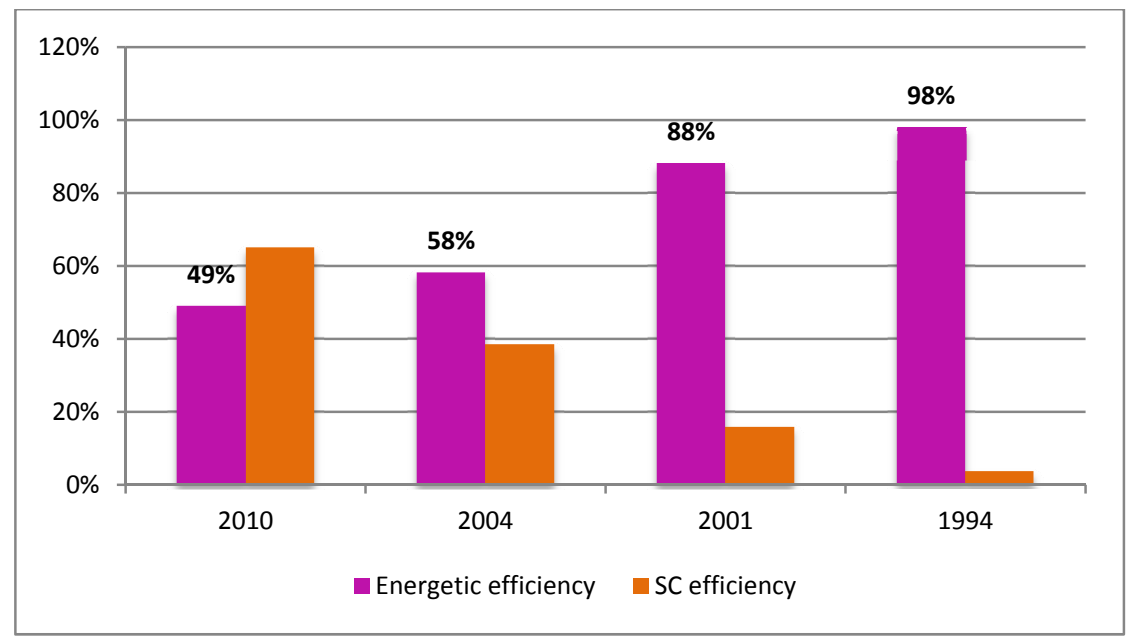

Figure 5: $\quad$ Energy exploitability (RMSW vs. MSW) and SC efficiency.

Apart from the opportunities of district heating, the potential of the incineration option is still interesting.

The 2010 RMSW characteristics (high LHV, low food waste content, overall amount lower than 100,000 t/y, expected low $\mathrm{Hg}$ and $\mathrm{Cl}$ content [27]) recently opened a local discussion on the viability of a direct classification of RMSW as SRF to be sent into existing plants also out of the provincial territory. This is a demonstration of how an extreme SC can affect the Waste-to-Energy strategies in the MSW sector. 


\section{Conclusions}

SC can cause significant indirect modifications of RMSW that can become similar to a SRF, opening to direct co-combustion opportunities in existing industrial plants (cement factories, thermal power plants, etc.). This pathway could decrease the cost of solutions alternative to direct combustion in dedicated plants (incinerators).

In spite of its high LHV, the energy exploitable, compared to MSW, is significantly reduced as effect of SC. That decreases the incineration scale to a value that must be well analyzed in terms of economic viability. Indeed incineration is affected by a significant scale effect that is more relevant for low plant capacity. The parallel increase of food waste SC opens to interesting energy recovery by anaerobic digestion. Of course the viability of this strategy needs a steady cooperation of the citizens that must guarantee an efficient separation of food waste.

From the above-presented scenarios, it is clear that the MSW management evolved to a waste-to-energy configuration (thanks to the direct and indirect generation of biogas and SRF-like) integrated with mass valorization (thanks to the SC optimization).

\section{Acknowledgements}

The author wishes to acknowledge PAT (Provincia Autonoma di Trento Autonomous Province of Trento, Italy) and Mr. Zatelli, in particular, for the support in data availability.

\section{References}

[1] Geourgescu-Roegen, N. Energy and economic myths, Southern Economic Journal, 41, pp. 347-381, 1998.

[2] Morejon, C.F.M., De Lima, J.F., Da Rocha Jr, W.F., Possa, R.D.New model of municipal solid waste management, International Journal of Environment and Sustainable Development, 11(3), pp. 238-248, 2012.

[3] McCollough, J. Determinants of a throwaway society - A sustainable consumption issue, Journal of Socio-Economics, 41/1, pp. 110-117, 2012.

[4] CAC -Cooperativa Atlantide di Cervia, Progetto scuola città, Rifiuti: Energia del futuro, 1998, www.atlantide.net

[5] Santoloci, M. and Vattani, V. Rifiuti solidi e liquidi: gestione, trasporto, stoccaggio, depositi \& dintorni, Diritto all'Ambiente Edizioni, Terni, pp. 1233, 2009.

[6] Mazodier, J. Reuse and recuperation of municipal wastes, Techn. Sci. Munic.70/7, pp. 289-295, 1975.

[7] Pieters, F., Verheyen, G. Selective collection of materials from garbage, Extern Tijdschriftvoor Omgevingswetenschappen, 8/4, pp. 193-207, 1979.

[8] Trondle, E. Selective collection, NATUROPA, 58, pp. 18-19,1988. 
[9] Golueke, C.G., Gotaas, H. B. Public health aspects of waste disposal by composting. American Journal of Public Health, 44/3, pp. 339-348, 1954.

[10] Gotaas, H. B. Composting; sanitary disposal and reclamation of organic wastes.Monographseries. World Health Organization,31, pp. 1-205, 1956.

[11] Bannink, H.F. and Muller, F.M. On the utilization of waste liquors from the digestion of straw with monosulphite, Antonie van Leeuwenhoek, 18/1, pp. 45-54, 1952.

[12] Johnson, G.E., Kunka, L.M., Decker, W.A., Forney, A.J. Production of methane by the anaerobic decomposition of garbage and waste materials.AmChemSoc, DivFuelChem, 16/4, pp. 70-78, 1972.

[13] Klass, D.L. and Ghosh, S. Fuel gas from organic wastes, CHEMTECH, pp. 689-698, 1973.

[14] Dennis, R., Muller, F.L., Kristal, E., Silverman, L. Special incineration studies - institutional design. ORINS Reports. U.S. Atomic Energy Commission 7593, pp. 344-364, 1960.

[15] Norwood Cook, E., Foree, E.G. Aerobic biostabilization of sanitary landfill leachate, Journal of the Water Pollution Control Federation,46/2, pp. 380$392,1974$.

[16] Adani, F., Scatigna, L., Genevini, P.Biostabilization of mechanically separated municipal solid waste fraction, Waste Management and Research, 18/5, pp. 471-477, 2000.

[17] Adani, F., Baido, D., Calcaterra, E., Genevini, P.The influence of biomass temperature on biostabilization-biodrying of municipal solid waste, Bioresource Technology, 83/3, pp. 173-179, 2002.

[18] Rada, E.C., Ragazzi, M., Panaitescu, V., Apostol, T.Experimental characterization of municipal solid waste bio-drying, WIT Transactions on Ecology and the Environment, 92, pp. 295-302, 2006.

[19] Choi, H.L., Richard, T.L., Ahn, H. K. Composting high moisture materials: Biodrying poultry manure in a sequentially fed reactor, Compost Science and Utilization, 9/4, pp. 303-311, 2001.

[20] E.C. and Ragazzi M., Critical analysis of PCDD/F emissions from anaerobic digestion, Water Science and Technology, 58.9, pp. 1721-1725, 2008.

[21] Rada E.C., Ragazzi M., Zardi D., Laiti L., Ferrari A., PCDD/F environmental impact from municipal solid waste bio-drying plant, Chemosphere, 84/3, pp. 289-295, 2011.

[22] Ragazzi M. and Rada E.C., Multi-step approach for local environmental impact comparison among conventional and innovative MSW thermochemical treatments, Chemosphere, 89/6, pp. 694-701, 2012.

[23] Torretta V., Ragazzi M., Istrate I., Rada E.C., Management of waste electronic and electronic equipment's in two EU countries: a comparison, Waste Management, 33/1, pp. 117-122, 2013.

[24] Da Cruz, N.F., Simões, P., Marques, R.C.Economic cost recovery in the recycling of packaging waste: The case of Portugal, Journal of Cleaner Production, 37, pp. 8-18, 2012. 
[25] Rada E.C., Ragazzi M., Fedrizzi P.: WEB-GIS oriented system viability for Municipal Solid Waste collection optimization in developed and transient economies, Waste Management, 33/4, pp. 785-792, 2013.

[26] Raicu, S., Costescu, D., Roşca, E., Popa, M.Optimal planning of selective waste collection, WIT Transactions on Ecology and the Environment, 150, pp. 785-794, 2011.

[27] Rada E.C. and Andreottola G., RDF/SRF: which perspectives for its future in the EU, Waste Management, 32/6, pp. 1059-1060, 2012. 